\title{
A Competitive Index Assay Identifies Several Ralstonia solanacearum Type III Effector Mutant Strains with Reduced Fitness in Host Plants
}

\author{
Alberto P. Macho, ${ }^{1}$ Alice Guidot, ${ }^{2}$ Patrick Barberis, ${ }^{2}$ Carmen R. Beuzón, ${ }^{1}$ and Stéphane Genin ${ }^{2}$ \\ ${ }^{1}$ Instituto de Hortofruticultura Subtropical y Mediterranea, Universidad de Málaga-Consejo Superior de Investigaciones \\ Científicas (IHSM-UMA-CSIC), Depto. Biología Celular, Genética y Fisiología, Campus de Teatinos, Málaga E-29071, \\ Spain; ${ }^{2}$ Laboratoire des Interactions Plantes Micro-organismes (LIPM), UMR CNRS-INRA 2594/441, F- 31320 Castanet \\ Tolosan, France
}

Submitted 11 March 2010. Accepted 29 April 2010.

\begin{abstract}
Ralstonia solanacearum, the causal agent of bacterial wilt, is a soil bacterium which can naturally infect a wide range of host plants through the root system. Pathogenicity relies on a type III secretion system which delivers a large set of approximately 75 type III effectors (T3E) into plant cells. On several plants, pathogenicity assays based on quantification of wilting symptoms failed to detect a significant contribution of $R$. solanacearum T3E in this process, thus revealing the collective effect of $\mathrm{T} 3 \mathrm{E}$ in pathogenesis. We developed a mixed infection-based method with $R$. solanacearum to monitor bacterial fitness in plant leaf tissues as a virulence assay. This accurate and sensitive assay provides evidence that growth defects can be detected for T3E mutants: we identified 12 genes contributing to bacterial fitness in eggplant leaves and 3 of them were also implicated in bacterial fitness on two other hosts, tomato and bean. Contribution to fitness of several T3E appears to be host specific, and we show that some known avirulence determinants such as popP2 or avrA do provide competitive advantages on some susceptible host plants. In addition, this assay revealed that the $e f e$ gene, which directs the production of ethylene by bacteria in plant tissues, and $h d f B$, involved in the biosynthesis of the secondary metabolite 3-hydroxyoxindole, are also required for optimal growth in plant leaf tissues.
\end{abstract}

Ralstonia solanacearum, the causative agent of bacterial wilt of solanaceous plants, is responsible for some of the most devastating bacterial plant diseases in the world.

The high economic and social impact of this organism results from its wide geographical distribution in all warm and tropical countries of the globe. This impact also results from the very wide host range of $R$. solanacearum, which comprises over 200 plant species representing over 50 botanical families and covering both monocots and dicots (Allen et al. 2005; Denny 2006).

As a soilborne plant pathogen, $R$. solanacearum naturally infects plants via the roots. Bacteria infect tomato plants through root tips and lateral root cracks, and rapidly develop within intercellular spaces of the inner cortex. Intercellular infection extends to the vascular parenchyma to finally invade protoxy-

A. P. Macho and A. Guidot contributed equally to this work.

Corresponding author: S. Genin; E-mail: sgenin@toulouse.inra.fr lem vessels via cell wall degradation (Vasse et al. 1995, 2000). After colonization of the xylem vessels, the bacteria multiply heavily, thus allowing their migration toward the aerial part of the plant. At this stage, abundant production of bacterial exopolysaccharides (EPS) in the vascular tissues correlates with appearance of typical wilting symptoms and, eventually, plant death (Saile et al. 1997).

Many gene products are required by $R$. solanacearum for successful infection of its hosts. Virulence factors, in addition to EPS production, include various plant cell-wall-degrading enzymes exported by the type II secretion pathway, and their expression is controlled by a complex virulence network (Schell 2000; Genin and Boucher 2002). An essential pathogenicity determinant is the type III secretion system (T3SS) because the corresponding mutant strains induce no disease symptoms on plants. Although T3SS mutant strains have in vitro growth similar to the wild type, they are weakly invasive in susceptible hosts and their multiplication in plant tissues is considerably reduced, up to $10^{4}$-fold less than the wild-type strain (Vasse et al. 2000; Genin and Boucher 2004). The T3SS directs the translocation of type III effector (T3E) proteins into the plant cell cytoplasm (Cunnac et al. 2004; Mukaihara and Tamura 2009). Studies performed in the sequenced strain GMI1000 have identified, to date, more than 40 T3E proteins transiting through this pathway and the likely number of substrates is estimated to be approximately 75 (Mukaihara and Tamura 2009; Poueymiro and Genin 2009). Three of these $\mathrm{T} 3 \mathrm{E}$ have been reported to behave as avirulence factors because they are detected by the plant immune systems through the products of resistance genes; this is the case for both the popP1 and avrA gene products on various Nicotiana spp. (Carney and Denny 1990; Poueymiro et al. 2009) and the avirulence protein PopP2, which physically interacts with the Arabidopsis RRS1-R resistance protein (Deslandes et al. 2003).

In recent years, genome sequence analyses and transcriptomic approaches have unraveled many additional $R$. solanacearum virulence gene candidates through the identification of the targets of key pathogenicity regulators (Genin and Boucher 2002; Valls et al. 2006). For example, strain GMI1000 produces the phytohormone ethylene (Valls et al. 2006) and a small diffusible indole-derived molecule named $h r p B$-dependent diffusible factor (Hdf) (Delaspre et al. 2007) that are produced in planta because their expression is transcriptionally controlled by the plant-induced T3SS gene regulators (Aldon et al. 2000). However, a role in virulence for ethylene or Hdf 
could not be established because the resulting mutant strains did not significantly differ from the wild type in their pathogenic behavior. A similar observation was made with most of the mutant strains carrying individual disruption of T3E: only 2 of 52 strains tested were found to be slightly affected in virulence on tomato (Cunnac et al. 2004), thus revealing an important functional overlap among this $\mathrm{T} 3 \mathrm{E}$ repertoire. In fact, contribution for virulence of GMI1000 T3E has been reported only for cumulative disruption mutants or in the case of a gene that determines virulence only on a specific host (Angot et al. 2006).

In other bacterial plant pathogens, there are several reports that a single disruption of a T3E gene is sufficient to significantly decrease the multiplication of the pathogen in planta (Kearney and Staskawicz 1990; Ritter and Dangl 1995; Losada et al. 2004; Jiang et al. 2009) or lead to reduced symptoms (Lorang et al. 1994; Bai et al. 2000; Lim and Kunkel 2005; Boureau et al. 2006). These observations suggest that the absence of a detectable virulence phenotype on plants with $R$. solanacearum $\mathrm{T} 3 \mathrm{E}$ mutant strains may somehow reflect a lack of sensitivity of the experimental system used (i.e., pathogenicity assays on whole plants with scoring of disease symptoms). The objective of this work was to develop a sensitive and reliable assay that allows quantifying a differential fitness of $R$. solanacearum strains in planta. Previous work with bacterial pathogens of animals (Freter et al. 1981; Taylor et al. 1987) and the leaf-born pathogen Pseudomonas syringae (Macho et al. 2007, 2009) has shown that, using the appropriate conditions, two strains within a mixed infection have the same probability to multiply as they have in individual infections. This finding paved the way for the development of competitive assays in vivo which can be accurately quantified through the determination of a competitive index (CI) (Baümler et al. 1997; Beuzón and Holden 2001). CI was defined as the mutant/wild-type ratio within the output sample divided by the corresponding ratio in the inoculum (Freter et al. 1981). In such in vivo competitive assays, the wild-type and mutant strains are co-inoculated in the same plant, thus reducing plant-to-plant variation and enhancing sensitivity in the detection of differential fitness between the two strains.

In this study, we used strain competition assays in mixed infections to measure the contribution of more than $15 \mathrm{R}$. solanacearum $\mathrm{T} 3 \mathrm{E}$ in the ability to grow efficiently in leaf tissues. We do provide evidence that CI assays using mixed infections in leaf tissues allow us to unravel the contribution to bacterial fitness for several $R$. solanacearum T3E for which previous work failed to reveal a role in pathogenicity on the basis of disease symptom development assays. The role of several T3E in promoting bacterial growth in planta appears to be host specific, and we show that some avirulence determinants such as popP2 or avrA do contribute to parasitic fitness on some susceptible host plants.

\section{RESULTS}

\section{Development of an $R$. solanacearum}

strain competition assay in tomato and eggplant leaves.

In order to accurately control the effective dose of bacterial inoculum introduced in host plants, we used an inoculation method consisting of the injection of a bacterial suspension into plant leaves using a blunt syringe. This leaf infiltration method was previously reported to be suitable to measure bacterial growth in planta of a vascular pathogen such as $R$. solanacearum (Sequeira and Hill 1974). We infiltrated susceptible tomato leaves with $100 \mu$ of a bacterial suspension containing the $R$. solanacearum GMI1485 strain at $10^{4} \mathrm{CFU} / \mathrm{ml}$, a GMI1000 de- rivative carrying a kanamycin resistance cassette that does not affect virulence (Vasse et al. 2000). Bacterial measurements 5 days postinoculation (dpi) showed that the bacterial population was able to grow up to $10^{8} \mathrm{CFU} / \mathrm{g}$ of leaf tissue (Fig. 1A, left panel). When the nonpathogenic mutant strain GMI1694 carrying a knockout mutation in $h r c V$, an essential T3SS structural gene, was inoculated in the same conditions, the population was only able to reach $10^{5} \mathrm{CFU} / \mathrm{g}$ (Fig. 1A, left panel). This results show that the fully virulent strain is actively growing up to high population numbers in the leaf tissue and that this growth is dependent on a functional T3SS.

Inoculation dose is an important factor conditioning potential interference between co-inoculated strains when infiltrated into plant leaves. Interference takes place when using a high dose of inoculum $\left(5 \times 10^{7} \mathrm{CFU} / \mathrm{ml}\right)$ to infiltrate mixed inocula of $P$. syringae, whereas lower doses $\left(10^{3}\right.$ to $5 \times 10^{4} \mathrm{CFU} / \mathrm{ml}$, depending on the host plant) completely avoid this interference (Macho et al. 2007). To determine whether our conditions in $R$. solanacearum leaf infiltration were adequate to avoid interference between two strains in a mixed infection, we infiltrated tomato leaves with a mixed suspension containing equal amounts of the GMI1485 strain and the GMI1694 mutant strain. Bacteria were then enumerated at 5 dpi and differentiated using antibiotic selection. Both strains in the mixed infection were able to grow as in individual infections (Fig. 1A, right panel). Because the CI is defined as the mutant/wild-type ratio within the output sample divided by the corresponding ratio in the inoculum (Freter et al. 1981), a CI = 1 would reflect that the mutant strain is able to grow as efficiently as the wild type, and a $\mathrm{CI}<1$ would indicate that growth of the mutant strain is attenuated. When the CI was calculated, it reflected a log difference of 3 between both strains (Fig. 1B). The same inocula were used to infiltrate $100 \mu \mathrm{l}$ of bacterial suspensions into susceptible eggplant leaves. Results show a dynamic similar to that obtained in tomato plants with more than a log difference of 4 in bacterial growth between the inoculated strains in both individual and mixed infections (Fig. $1 \mathrm{C}$ and D).

Finally, a control experiment was carried out to test whether mixed inoculation affects the growth of two equally virulent bacteria. Single and mixed inoculations were performed using the wild-type strain GMI1000 and the GMI1485 kanamycinresistant derivative. Both strains grew at the same level in single and mixed inoculations in both tomato and eggplant (Fig. 2 ), confirming that the population inoculated under the experimental conditions used was not affected by limiting thresholds or genetic drift and did not result in a bias in fitness between the two equally virulent bacterial strains. Altogether, these results validate the use of leaf infiltration to carry out fitness analysis by mixed infections in both tomato and eggplant.

\section{Impact of the plant inoculation method on the strain competition assay.}

Different infection modes are routinely used for pathogenicity assays with $R$. solanacearum: one consists of a direct stem injection of bacteria (Roberts et al. 1988) and the second is a soil-drenching assay which more closely mimics the natural infection process. We were interested in determining whether competition assays in mixed infections could also be performed using these two inoculation procedures. For the soil-drenching inoculation method, plants were watered with an inoculum of $50 \mathrm{ml}$ of a bacterial suspension at $5 \times 10^{7} \mathrm{CFU} / \mathrm{ml}$ and bacterial growth was monitored at $5 \mathrm{dpi}$ on the aerial parts of the plants. As expected, the $h r c V$ mutant strain GMI1694 reached a population approximately 2,500-fold lower than that reached by the wild-type GMI1485 in individual infections (Fig. 3A). However, in mixed infections, the $h r c V$ mutant was able to multiply 1,500 times more than in individual infections, indicating 
that the presence of the wild-type strain enhanced growth of the mutant strain. In order to avoid this complementation effect, we performed soil-drenching inoculation assays with a reduced bacterial inoculum $\left(1 \times 10^{7}\right.$ and $\left.5 \times 10^{6} \mathrm{CFU} / \mathrm{ml}\right)$ but growth interference was observed again, because populations of strain GMI1694 were higher (by several orders of magnitude) each time in mixed infections than in individual infections (Fig. $3 \mathrm{~A})$. With the $5 \times 10^{6} \mathrm{CFU} / \mathrm{ml}$ inoculation dose, no infection was detected for GMI1694 in individual infections but, after co-inoculation with the wild type, the mutant was found in planta at significant levels. At lower inoculation doses $\left(1 \times 10^{6}\right.$ $\mathrm{CFU} / \mathrm{ml}$ ), infection of plants became more stochastic because only $20 \%$ of the plants were wilted by the wild-type GMI 1485 (data not shown), indicating that the starting inoculum was below the critical threshold to ensure reproducible infection.

We then performed infection by a direct stem-inoculation procedure; in this method, $10 \mu \mathrm{l}$ of bacterial suspensions ranging from $10^{6}$ to $10^{4} \mathrm{CFU} / \mathrm{ml}$ were injected into the stem with a syringe and bacteria in the aerial part of plant tissues were enumerated at 5 dpi. Here, again, we observed that the bacterial growth of the GMI1694 ( $h r c V$ ) mutant strain was significantly enhanced in mixed infection compared with individual infection (Fig. 3B), indicating that interference with the wildtype strain occurs in these conditions. Rather remarkably, this phenomenon was observed until an extremely low inoculum dose (approximately 100 bacterial cells), which indicates that competitive growth assays using mixed infections in stem-injection conditions can be severely affected by strain interference and, therefore, would not constitute a reliable virulence assay.

\section{Identification of 12 GMI1000 T3E mutant strains with reduced fitness in eggplant leaves.}

Because mixed infections in leaf tissues provided a sensitive and quantifiable assay for measuring bacterial growth in planta, we decided to use this method to analyze the behavior of several GMI1000 T3E or other T3SS-associated genes. In total, 18 GMI1000 mutant strains were selected (Table 1); this list included 2 T3E mutant strains for which a weak hypovirulent phenotype was previously reported, GRS72 (RSp0304) and GRS76 (RSp0099) (Cunnac et al. 2004) and 14 mutant strains for which no difference in pathogenicity was observed compared with the wild-type strain after root inoculation of tomato plants. This list also included mutant strains in two suspected pathogenicity determinants encoding for production of
A

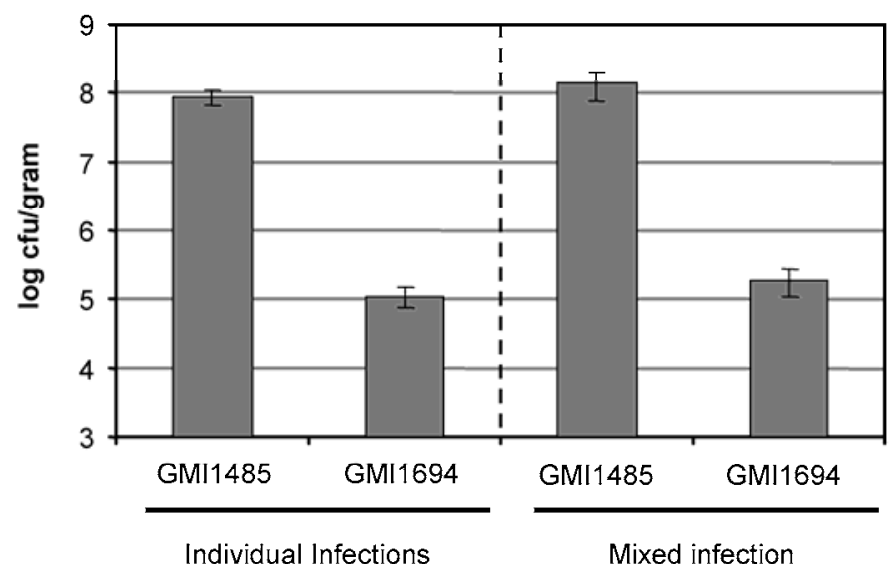

C

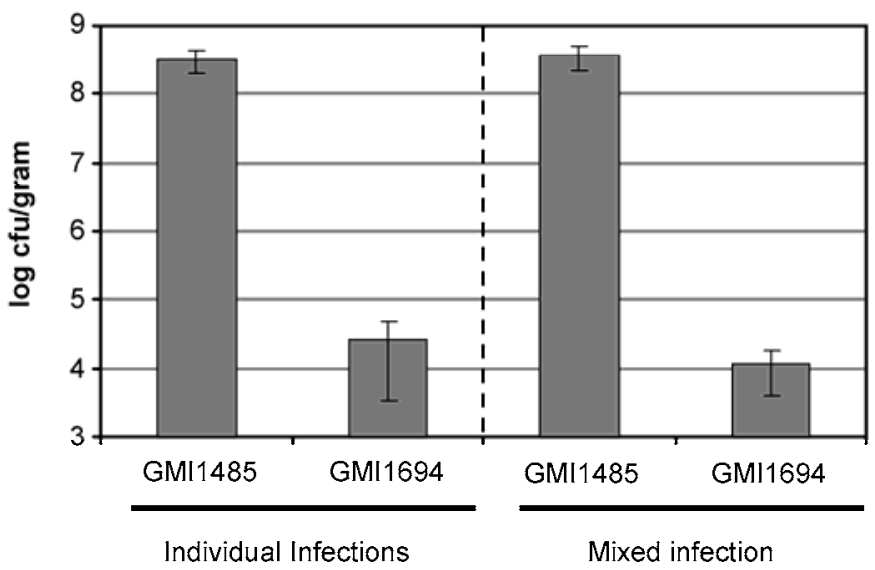

B

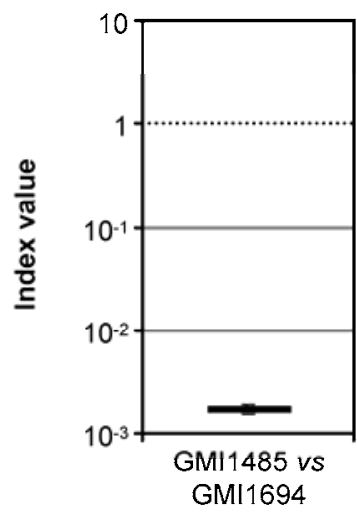

D

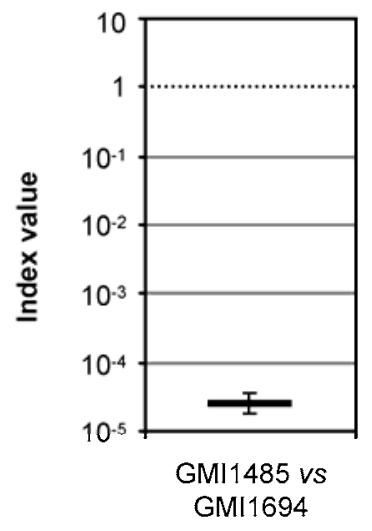

Fig. 1. Bacterial growth and competitive index (CI) values of GMI1485 versus GMI1694 strains of Ralstonia solanacearum individually or mixed inoculated in tomato and eggplant leaves. The GMI1485 strain is a derivative of the wild-type GMI1000 strain carrying a kanamycin resistance cassette that does not affect virulence. The GMI1694 strain is a nonpathogenic mutant of GMI1000 carrying a knockout mutation in $h r c V$, an essential type III secretion system structural gene. A, Bacterial growth of GMI1485 and GMI1694 at 5 days postinoculation (dpi), either individually inoculated (left panel) or co-inoculated (right panel) in tomato by leaf infiltration. B, CI mean value generated from mixed inoculation of GMI1485 and GMI1694 in tomato leaves. C, Bacterial growth of GMI1485 and GMI1694 at 5 dpi, either individually inoculated (left panel) or co-inoculated (right panel) in eggplant by leaf infiltration. D, CI mean value generated from mixed inoculation of GMI1485 and GMI1694 in eggplant leaves. Each mean value in A and C represents the log of the mean of CFU values obtained from five plants. Each mean value in B and D represents the mean CI values from five plants co-inoculated with GMI1485 and GMI1694. Error bars represent the standard error. 
the phytohormone ethylene (GMI1769) (Valls et al. 2006) and the small diffusible molecule $\operatorname{Hdf}$ (i.e., 3-hydroxy-oxindole [GRS407]) (Delaspre et al. 2007).

First, pathogenicity of these 18 mutant strains was compared with the wild-type GMI1000 on eggplant by the soil-drenching assay. This analysis did not reveal any attenuation in the rate of wilting symptoms for any of the mutant strains tested (data not shown). We then investigated the behavior of each of these mutants in competition assays with the wild-type strain GMI1000 on eggplant leaves in two or three independent experiments using $100 \mu \mathrm{l}$ of a $10^{4} \mathrm{CFU} / \mathrm{ml}$ mixed suspension containing equal amounts of both strains. Bacteria were then enumerated at $5 \mathrm{dpi}$ and differentiated using antibiotic selection. Rather surprisingly, we found that most of the mutant strains exhibited CI values significantly less than 1 (Student's $t$ test, $P$ value $<0.05$ ) indicating that their fitness in eggplant tissues was reduced; only four mutant strains (GALA7, avrA, $R S c 1475$, and $R S p 0099$ ) had a multiplication rate comparable with GMI1000 (Table 2). Three classes of mutant strains altered in fitness on eggplant can be distinguished considering the range of CI values: a first class corresponded to strongly attenuated mutants $(R S p 0304$ and popP2) with $\mathrm{CI}<0.2$, a second class comprised nine mutant strains with a CI ranging between 0.2 and 0.4 , and a third class of mutants was moderately reduced in fitness (CI between 0.4 and 0.6). This latter class comprised the ethylene-forming enzyme (efe) mutant strain; although expression of the efe gene was known to be under the transcriptional control of the pathogenicity regulator HrpG, this is the first evidence that ethylene production by $R$. solanacearum promotes bacterial growth in planta.

\section{Contribution to bacterial fitness}

of several T3E genes is host specific.

In order to determine the impact of the host plant on bacterial fitness after infiltration of leaf tissues, we carried out competition experiments, similar to those above, between a subset of 11 mutant strains and GMI1000 on two other hosts, tomato and bean. Bean was chosen as a non-solanaceous host which is tolerant to strain GMI1000; that is, the bacterium is able to multiply to a significant level in the plant (up to $10^{8} \mathrm{CFU} / \mathrm{g}$ of fresh weight) but without (or only occasionally) causing wilting symptoms. Leaf tissues were infiltrated with $100 \mu$ of mixed suspensions at $10^{4} \mathrm{CFU} / \mathrm{ml}$ and mutant/wild-type CI ratios were determined after enumeration by serial plating at 5
A Leaf infiltration on tomato

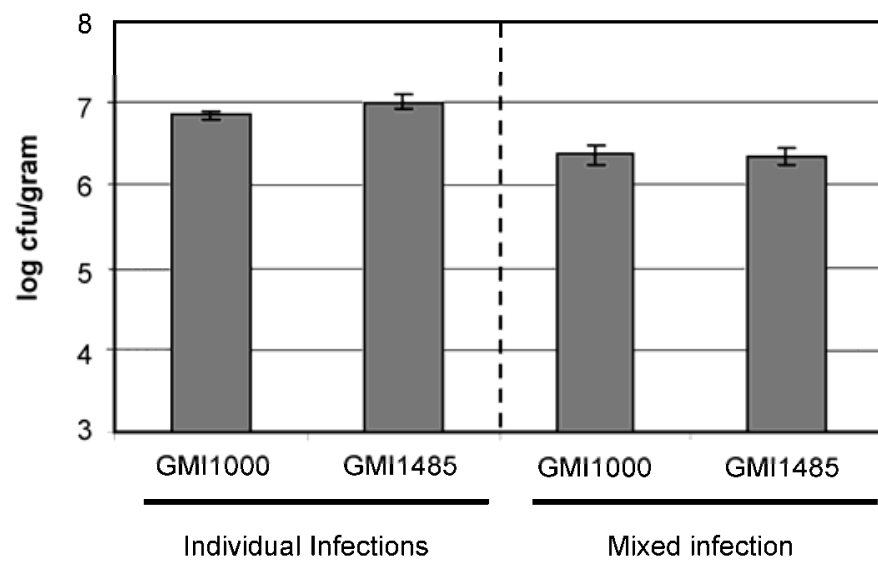

C

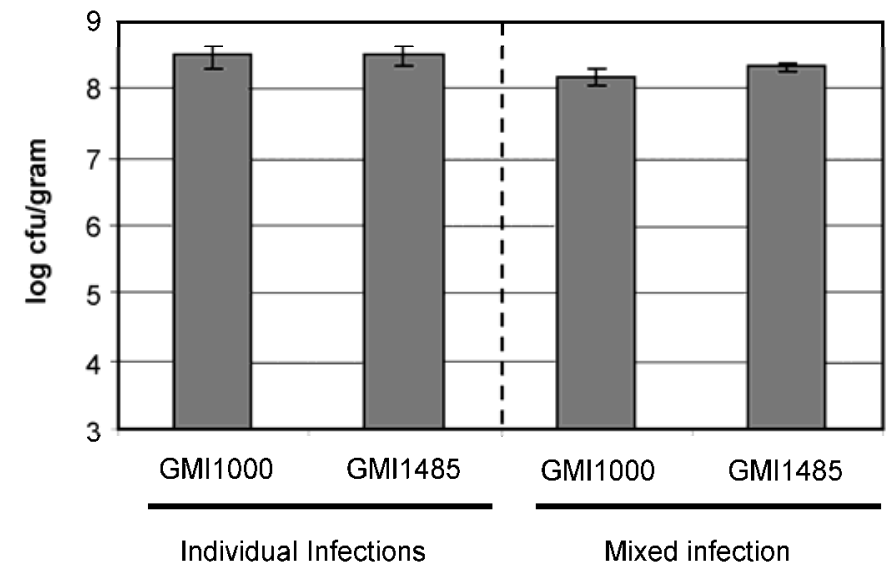

B

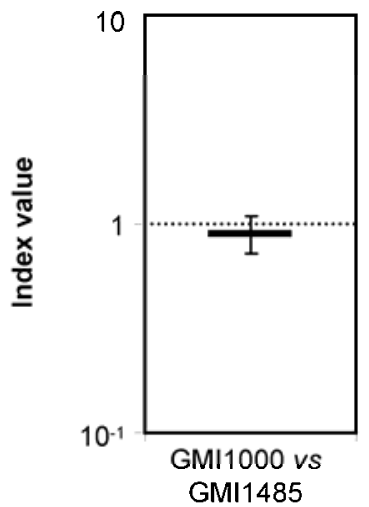

$\mathrm{D}$

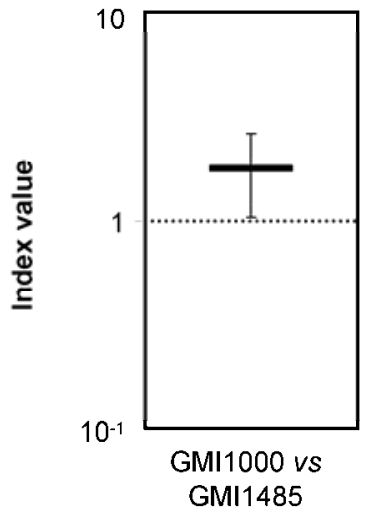

Fig. 2. Bacterial growth and competitive index (CI) values of GMI1000 versus GMI1485 strains of Ralstonia solanacearum individually or mixed inoculated in tomato and eggplant leaves. GMI1485 is a derivative of the wild-type GMI1000 strain carrying a kanamycin resistance cassette that does not affect virulence. A, Bacterial growth of GMI1000 and GMI1485 at 5 days postinoculation (dpi), either individually inoculated (left panel) or co-inoculated (right panel) in tomato by leaf infiltration. B, CI mean value generated from mixed inoculation of GMI1000 and GMI1485 in tomato leaves. C, Bacterial growth of GMI1000 and GMI1485 at 5 dpi, either individually inoculated (left panel) or co-inoculated (right panel) in eggplant by leaf infiltration. D, CI mean value generated from mixed inoculation of GMI1000 and GMI1485 in eggplant leaves. Each mean value in A and C represents the log of the mean of CFU values obtained from five plants. Each mean value in B and D represents the mean CI values from five plants co-inoculated with GMI1000 and GMI1485. Error bars represent the standard error. 
dpi. On tomato, four mutant strains were found to multiply less efficiently than the wild-type because the determined CI values differed significantly from 1 (Student's $t$ test, $P$ value $<$ 0.05) (Table 3). Fitness of the avrA mutant was strongly altered in this host whereas it was not affected in eggplant. The $R S p 0304$ and $h d f B$ mutants were scored as less competitive in this condition, as in eggplant tissues, and one remaining mutant (popP2) was moderately affected.

On bean, a rather similar picture was observed but not exactly involving the same players: three mutant strains with reduced fitness on tomato and eggplant were also reduced in fitness on bean $(R S p 0304$, popP2, and $h d f B)$ whereas the fitness contribution of two other T3E was specific of this host ( RSp0822 and $R S p 0842$ ). Altogether, these observations suggest that bacterial fitness inside a given host relies on different sets of T3E, and that the individual contribution of these T3E can vary from one plant to another.

\section{DISCUSSION}

Plant pathogenicity assays with soil root pathogens such as $R$. solanacearum have several limitations that hinder their use

A Soil-drenching inoculations

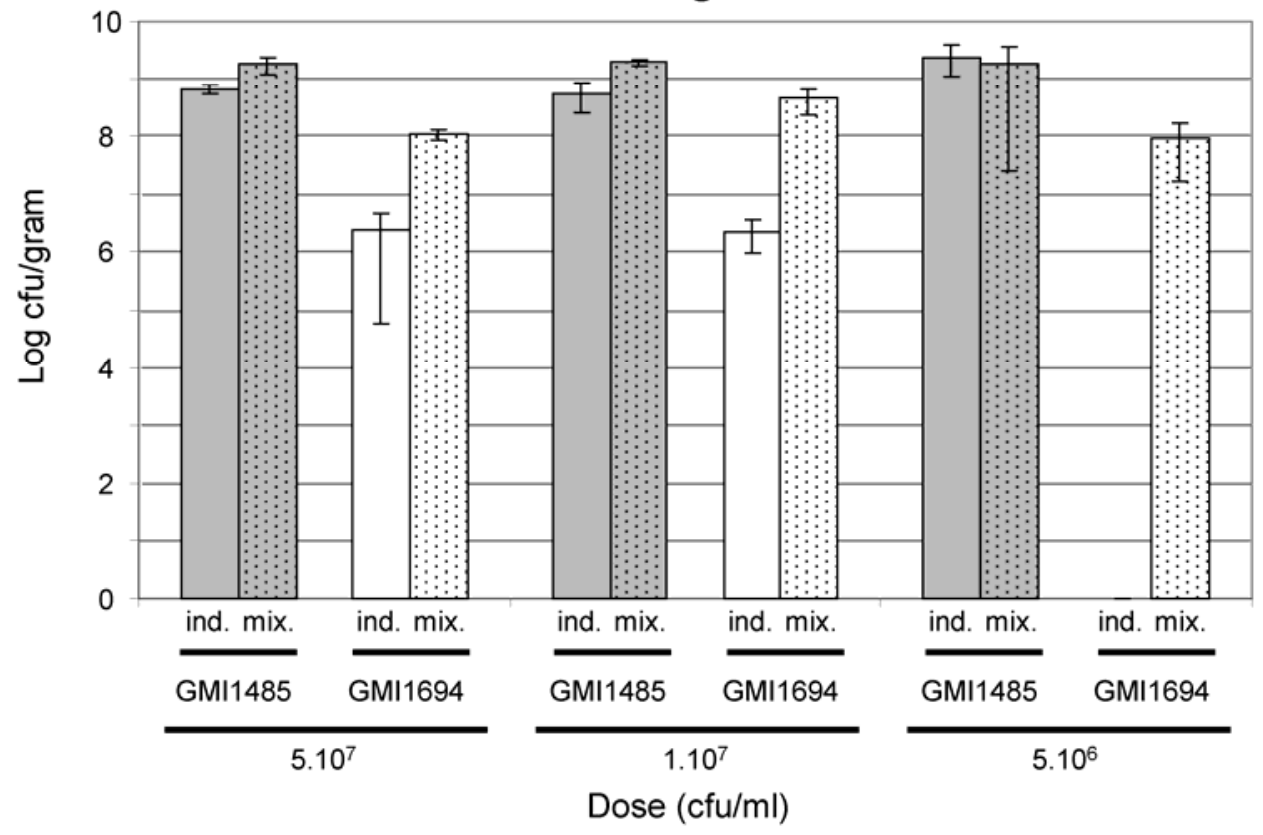

B

Stem injections

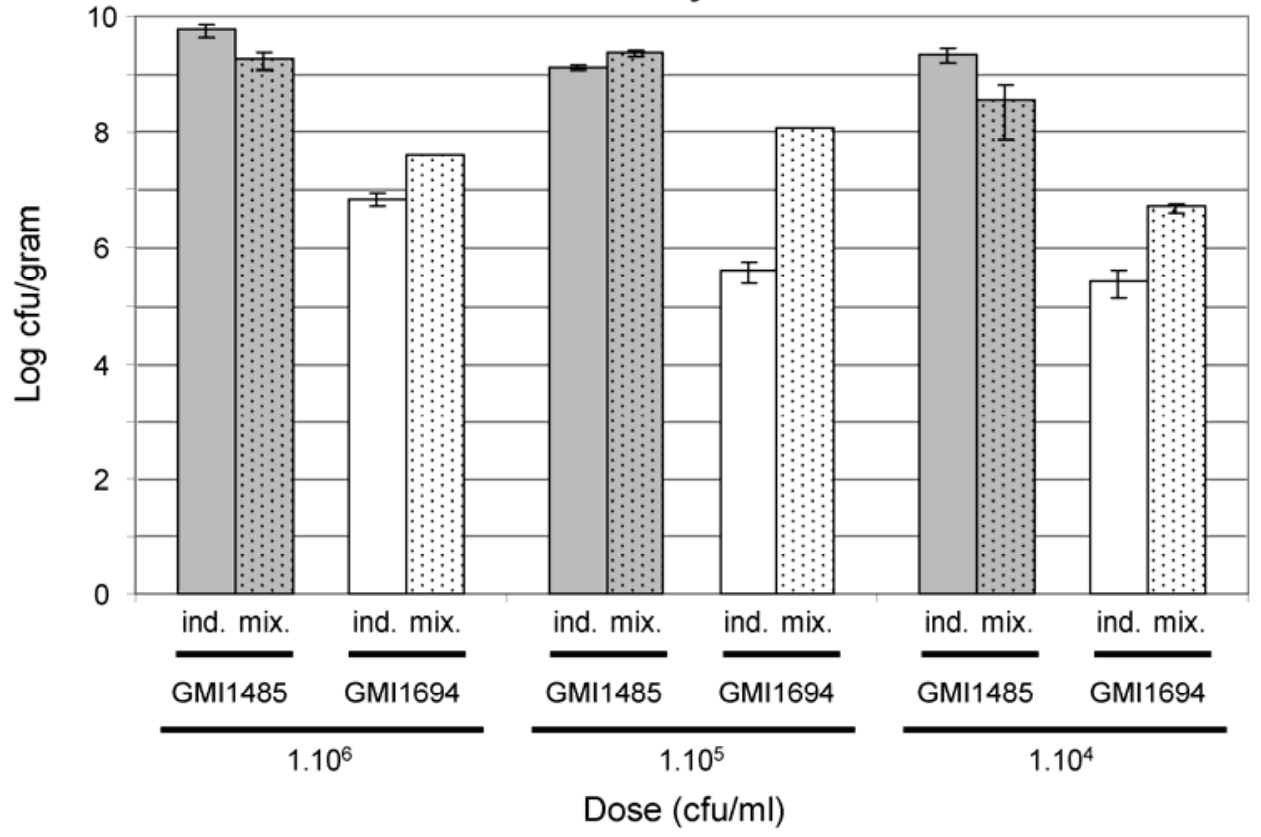

Fig. 3. Effect of inoculation dose on bacterial growth of GMI1485 versus GMI1694 strains of Ralstonia solanacearum individually or mixed inoculated in tomato by A, soil drenching or B, stem injection. The GMI1485 strain is a derivative of the wild-type GMI1000 strain carrying a kanamycin resistance cassette that does not affect virulence. The GMI1694 strain is a nonpathogenic mutant of GMI1000 carrying a knockout mutation in $h r c V$, an essential type III secretion system structural gene. Each mean value in A and B represents the log of the mean of CFU values obtained from five plants. Error bars represent the standard error; ind. = individual inoculation and mix. = mixed inoculation. 
for an accurate and sensitive phenotypic characterization of mutant strains. First, a main difficulty is to reproduce pathogen growth data because it is difficult even in growth chambers to ensure reproducibility of host plant material; in consequence, this always introduces a source of variation in the comparison of the pathogenic behavior of two distinct strains. Second, the soil-drenching inoculation method, which mimics the natural mode of infection of the pathogen through the soil, does not allow the exact determination of the beginning of the interaction and of the effective inoculum that enters the plant root system. This is also a cause of variation and renders impossible an accurate quantification of the bacterial multiplication in the plant. In this study, we set up a mixed infection-based competition assay in leaf tissues for $R$. solanacearum, based on the method previously developed with the epiphytic plant pathogen $P$. syringae (Macho et al. 2007). At sufficiently low inoculation doses (up to $10^{4} \mathrm{CFU} / \mathrm{ml}$ ), $R$. solanacearum replicates in leaf tissues at the same rate in mixed and individual infections, with no growth interference. However, our attempts to develop a mixed infection assay with the soil-drenching or stem-injection methods remained unsuccessful. For the soildrenching pathogenicity assay, the main limitation is the critical threshold of the bacterial inoculum: at less than $5 \times 10^{6}$ $\mathrm{CFU} / \mathrm{ml}$, infection will not evenly occur on each plant. Therefore, at such low concentrations, there may be a "founding effect" in which only a single or a few individuals of only one of the strains will carry out host colonization. At $10^{7} \mathrm{CFU} / \mathrm{ml}$, which is a low inoculum concentration for routine pathogenicity assays on whole plants (Cunnac et al. 2004), interference between the wild-type and hrp mutant strain was observed and the most probable reason for this is that the increased $h r p$ mutant populations collected from the aerial parts of plants at 5 dpi were complemented by the wild-type strain throughout the whole infectious process. In the case of stem injection assays, being presumably immediately present in xylem vessels, the $R$. solanacearum wild type is able to diffuse through the plant and to multiply very efficiently because, at $5 \mathrm{dpi}$, it is able to reach up to $10^{9} \mathrm{CFU} / \mathrm{g}$ of fresh weight in plants from a starting inoculum of approximately 100 bacteria. The observed complementation of the hrp mutant strain by the wild type at such an extremely low inoculum concentration (Fig. 3B) is probably due to the scarcity of feeding sites in vascular tissues. It is possible that hrp mutant bacteria benefit from the action of the wild type for suppressing plant defense responses and acquisition of nutrients from these feeding sites; therefore, no competition between the two strains occurs in these conditions. However, mixed-infection competition assays could be used following root infection if either the mutant strain cannot be complemented by the wild-type or interference between coinoculated strains is of interest for the analysis. In support of this, a previous study successfully used mixed infections to quantify the impact of chemotaxis genes on bacterial fitness (Yao and Allen 2006).

With the leaf infiltration experimental method, our results confirmed both the accuracy and the sensitivity of CI as a virulence assay. Clear differential growth rates in leaf tissues were quantified between the wild type and the hrp mutant strain in mixed infections $\left(10^{3}\right.$-fold or more), which correlates with the difference classically recorded in individual internal growth assays on several plants (Deslandes et al. 1998; Vailleau et al.

Table 2. Competitive index (CI) values of different GMI1000 mutants coinoculated with the wild-type GMI1000 strain in eggplant leaves

\begin{tabular}{llll}
\hline & & \multicolumn{2}{c}{ Eggplant $^{\mathbf{a}}$} \\
\cline { 3 - 4 } Strain & Genotype & CI & P value \\
\hline GMI1694 & $h r c V$ & $\mathbf{0 . 0 0 0 0 4 2}$ & $\mathbf{4 . 1 7 E - 2 5}$ \\
GRS72 & $R S p 0304$ & $\mathbf{0 . 1 3}$ & $\mathbf{3 . 7 8 E - 0 7}$ \\
GRS100 & $p o p P 2$ & $\mathbf{0 . 1 7}$ & $\mathbf{7 . 1 4 E - 0 6}$ \\
GRS242 & $R S c 0257$ & $\mathbf{0 . 2 2}$ & $\mathbf{1 . 2 7 E - 0 4}$ \\
GRS216 & $R S c 1815$ & $\mathbf{0 . 2 3}$ & $\mathbf{2 . 4 6 E - 0 4}$ \\
GMI1620 & $p o p C$ & $\mathbf{0 . 2 3}$ & $\mathbf{1 . 0 1 E - 0 4}$ \\
GRS407 & $h d f B$ & $\mathbf{0 . 2 7}$ & $\mathbf{1 . 6 3 E - 0 4}$ \\
GRS142 & $R S p 0822$ & $\mathbf{0 . 2 9}$ & $\mathbf{1 . 4 4 E - 0 4}$ \\
GRS170 & $R S c 2359$ & $\mathbf{0 . 2 9}$ & $\mathbf{6 . 1 5 E}-\mathbf{0 5}$ \\
GRS166 & $R S p 1022$ & $\mathbf{0 . 3 1}$ & $\mathbf{2 . 4 4 E - 0 5}$ \\
GRS164 & $R S p 0732$ & $\mathbf{0 . 3 1}$ & $\mathbf{1 . 9 5 E - 0 4}$ \\
GRS70 & $R S c 1839$ & $\mathbf{0 . 3 6}$ & $\mathbf{2 . 5 1 E - 0 4}$ \\
GMI1769 & efe & $\mathbf{0 . 4 9}$ & $\mathbf{7 . 7 7 E - 0 3}$ \\
GRS190 & $R S p 1281$ & $\mathbf{0 . 5 1}$ & $\mathbf{1 . 7 4 E - 0 3}$ \\
GRS230 & $R S p 0842$ & $\mathbf{0 . 5 8}$ & $\mathbf{5 . 0 1 E - 0 3}$ \\
GRS138 & GALA7 & 0.87 & $9.91 \mathrm{E}-02$ \\
GRS99 & $a v r A$ & 0.87 & $1.42 \mathrm{E}-01$ \\
GRS293 & $R S c 1475$ & 0.89 & $1.46 \mathrm{E}-01$ \\
GRS76 & $R S p 0099$ & 1.09 & $3.53 \mathrm{E}-01$ \\
\hline
\end{tabular}

${ }^{a}$ Values in bold indicate which results have been shown by statistical analysis to be significantly different from 1.0, as established using Student's $t$ test $(P$ value $<0.05)$.

Table 1. List of bacterial strains used in this study

\begin{tabular}{|c|c|c|}
\hline Strain & Genotype $^{a}$ & Reference \\
\hline GMI1000 & Ralstonia solanacearum, wild-type strain & Salanoubat et al. 2002 \\
\hline GMI1485 & GMI1000 derivative, $\mathrm{Km}^{\mathrm{r}}$ & Vasse et al. 2000 \\
\hline GMI1694 & GMI1000 derivative, $\operatorname{hrc} V:: \Omega, \mathrm{Spc}^{\mathrm{r}}$ & Cunnac et al. 2004 \\
\hline GMI1620 & GMI1000 derivative, popC::Tn5B20, $\mathrm{Km}^{\mathrm{r}}$ & Guéneron et al. 2000 \\
\hline GMI1769 & GMI1000 derivative, efe $: \Omega, \mathrm{Spc}^{\mathrm{r}}$ & Valls et al. 2006 \\
\hline GRS70 & GMI1000 derivative, $R S c 1839:: \mathrm{pCZ} 367, \mathrm{Gm}^{\mathrm{r}}$ & Cunnac et al. 2004 \\
\hline GRS72 & GMI1000 derivative, $R S p 0304:: \mathrm{pCZ} 367, \mathrm{Gm}^{\mathrm{r}}$ & Cunnac et al. 2004 \\
\hline GRS76 & GMI1000 derivative, $R S p 0099:: \mathrm{pCZ} 367, \mathrm{Gm}^{\mathrm{r}}$ & Cunnac et al. 2004 \\
\hline GRS99 & GMI1000 derivative, $\triangle a v r A, \mathrm{Gm}^{\mathrm{r}}$ & Cunnac et al. 2004 \\
\hline GRS100 & GMI1000 derivative, $\triangle p o p P 2, \mathrm{Gm}^{\mathrm{r}}$ & Deslandes et al. 2003 \\
\hline GRS138 & GMI1000 derivative, GALA7::pCZ367, $\mathrm{Gm}^{\mathrm{r}}$ & Angot et al. 2006 \\
\hline GRS142 & GMI1000 derivative, $R S p 0822:: \mathrm{pCZ} 367, \mathrm{Gm}^{\mathrm{r}}$ & Cunnac et al. 2004 \\
\hline GRS164 & GMI1000 derivative, $R S p 0732:: \mathrm{pCZ} 367, \mathrm{Gm}^{\mathrm{r}}$ & Cunnac et al. 2004 \\
\hline GRS166 & GMI1000 derivative, $R S p 1022:: \mathrm{pCZ} 367, \mathrm{Gm}^{\mathrm{r}}$ & Cunnac et al. 2004 \\
\hline GRS170 & GMI1000 derivative, $R S c 2359:: \mathrm{pCZ} 367, \mathrm{Gm}^{\mathrm{r}}$ & Cunnac et al. 2004 \\
\hline GRS190 & GMI1000 derivative, $R S p 1281:: \mathrm{pCZ} 367, \mathrm{Gm}^{\mathrm{r}}$ & Cunnac et al. 2004 \\
\hline GRS216 & GMI1000 derivative, $\Delta R S c 1815, \mathrm{Gm}^{\mathrm{r}}$ & Cunnac et al. 2004 \\
\hline GRS230 & GMI1000 derivative, $\Delta R S p 0842, \mathrm{Gm}^{\mathrm{r}}$ & Cunnac et al. 2004 \\
\hline GRS242 & GMI1000 derivative, $R S c 0257:: \mathrm{pCZ} 367, \mathrm{Gm}^{\mathrm{r}}$ & Cunnac et al. 2004 \\
\hline GRS293 & GMI1000 derivative, $R S c 1475: \mathrm{pCZ} 367, \mathrm{Gm}^{\mathrm{r}}$ & Cunnac et al. 2004 \\
\hline GRS407 & GMI1000 derivative, $h d f B:: \mathrm{pCZ} 367, \mathrm{Gm}^{\mathrm{r}}$ & Delaspre et al. 2007 \\
\hline
\end{tabular}

${ }^{\mathrm{a}} \mathrm{Km}^{\mathrm{r}}, \mathrm{Spc}^{\mathrm{r}}$, and $\mathrm{Gm}^{\mathrm{r}}$ indicate resistance to kanamycin, spectinomycin, and gentamicin, respectively. 
2007). A main objective of this work was to investigate whether $\mathrm{CI}$ assays were sensitive enough to unravel a role for T3E in contributing to optimal bacterial multiplication inside host tissues. The effectors are collectively essential but, are in most of the cases, individually dispensable for the ability to produce symptoms in plants. This may be due to a probable functional overlap among effectors but also to plant pathogenicity assays not being sensitive enough to reveal subtle phenotypic differences. Remarkably, the analysis of in vivo competitive growth between the wild-type strain and 18 mutant derivatives in eggplant leaf tissues revealed that 14 of them were less competitive, although to different degrees. We then tested 10 of these mutants in competition experiments with the wild type on two other plant leaf tissues (tomato and bean) and found that half of them were also significantly reduced in fitness. These results demonstrate that the use of mixed infections for competition experiments in planta is a valuable tool to detect individual contribution of T3E to bacterial fitness in a more sensitive manner than monitoring symptom development in pathogenicity assays. However, it should be kept in mind that competition experiments in plant leaf tissues is a way to monitor bacterial fitness in a specific environment and cannot be taken as a representative assay of $R$. solanacearum pathogenicity because several key infectious processes (including root entry, endodermis crossing, and vascular colonization) are bypassed by the inoculation method used.

In this study, two T3E, RSp0304 and popP2, were identified as required for efficient bacterial multiplication in the three host plants tested. In a previous study, wilting symptom development on tomato plants was reported to be slightly reduced for the RSp0304 and RSp0099 mutant strains compared with wild-type GMI1000 (Cunnac et al. 2004). For RSp0304, our data indicate that reduced pathogenicity is associated with a decreased growth rate in tomato. CI assays also reveal that this T3E, which belongs to the HopD1/AvrPphD family, appears to be a key determinant for fitness of GMI1000 in several hosts. In the case of RSp0099, no significant difference in growth rate was detected in competitive assays; therefore, it is possible that contribution of this $\mathrm{T} 3 \mathrm{E}$ is required in earlier or more specific stages of the pathogenic process. This study also shows that disruption of the $h d f B$ gene led to reduced in planta growth compared with the wild-type strain in each of the three plants tested. $h d f B$ encodes a tryptophan-dioxygenase required for the biosynthesis of Hdf, a small diffusible molecule identified as 3-hydroxy-oxindole (Delaspre et al. 2007). hdfB belongs to a five-gene operon under the transcriptional control of the T3SS regulator HrpB (Occhialini et al. 2005). Because no phenotype on plants could be associated with the $h d f B$ mutant (Delaspre et al. 2007), this is the first indication that bacterial production of 3-hydroxy-oxindole in planta contributes to $R$. solanacearum's fitness, although the role of this molecule in plants remains to be determined. Similarly, we found that disruption of the efe gene which directs the production of ethylene and succinate from oxoglutarate impairs growth of bacteria in eggplant leaf tissues. It was shown that the GMI1000 efe gene was sufficient to impact plant ethylene-responsive pathways (Valls et al. 2006), and results of the present study further suggest that production of this hormone in plants is important for bacterial pathogenicity.

This study also provides the first evidence that popP2, which encodes the avirulence protein recognized by the Arabidopsis RRS1-R resistance protein (Deslandes et al. 2003), is required for bacterial fitness on other hosts such as eggplant or bean. Similar results were also observed with the T3E avrA, which encodes the major avirulence determinant recognized by several tobacco species (Poueymiro et al. 2009); mixed infection assays show that avrA gives a strong competitive advantage, specifically in tomato. A role for avrA in early stages of root infection on the legume Medicago truncatula has also been recently reported (Turner et al. 2009). These observations support the view that avirulence ( $a v r)$ genes have a selective value on certain susceptible hosts, as already shown for several of them (Kearney and Staskawicz 1990; Swarup et al. 1991; Lorang et al. 1994; Ritter and Dangl 1995; Bai et al. 2000; Lim and Kunkel 2005). The positive role of $a v r A$ in the pathogenicity of $R$. solanacearum toward different hosts could also explain why this $a v r$ determinant is found in most of the strains tested within the species (Carney and Denny 1990; Poueymiro and Genin 2009).

Several other T3E were also found to be required for optimal growth in eggplant tissues, such as the leucine-rich repeatcontaining effector PopC, the ankyrin repeat-containing effector RSc0257, the AvrBs3 family member RSc1815, or the SKWP family member RSc1839 (Poueymiro and Genin 2009). However, the gala 7 gene, although essential for pathogenicity on M. truncatula (Angot et al. 2006; Turner et al. 2009), did not appear to provide a competitive advantage in eggplant, tomato, or bean leaf tissues, probably because its role is restricted to a specific host or only required at a particular step of the infection. Our study confirms that contribution to fitness of several T3E can vary significantly depending on the host; in addition to avrA (see above), there are other examples of T3E providing a competitive advantage only on a specific host plant, such as RSp0842 on bean or RSc2359 and RSc1839 on eggplant. This observation fits with the hypothesis that a widehost-range pathogen has to maintain large repertoires of T3E in order to be adapted to multiple hosts. Indeed, genome sequence analyses and comparative hybridization studies revealed that $>30 \mathrm{~T} 3 \mathrm{E}$ are highly conserved and widely distributed in various $R$. solanacearum strains differing in host range speci-

Table 3. Competitive index (CI) values of different GMI1000 mutants co-inoculated with the wild-type GMI1000 strain in tomato and bean leaves

\begin{tabular}{|c|c|c|c|c|c|}
\hline \multirow[b]{2}{*}{ Strain } & \multirow[b]{2}{*}{ Genotype } & \multicolumn{2}{|c|}{ Tomato } & \multicolumn{2}{|c|}{ Bean } \\
\hline & & CI & $P$ value & CI & $P$ value \\
\hline GMI1694 & $h r c V$ & 0.0017 & $5.47 \mathrm{E}-17$ & 0.00076 & $3.27 \mathrm{E}-13$ \\
\hline GRS72 & RSp0304 & 0.41 & 4.47E-06 & 0.58 & 7.42E-04 \\
\hline GRS100 & рорР2 & 0.82 & 7.13E-04 & 0.42 & 8.37E-05 \\
\hline GRS407 & $h d f B$ & 0.48 & 2.05E-03 & 0.44 & $1.67 \mathrm{E}-03$ \\
\hline GRS142 & RSp0822 & 1.08 & $1.79 \mathrm{E}-01$ & 0.58 & 1.52E-02 \\
\hline GRS170 & $R S c 2359$ & 0.92 & $1.94 \mathrm{E}-01$ & 1.22 & $2.08 \mathrm{E}-01$ \\
\hline GRS70 & RSc1839 & 0.90 & 2.19E-01 & 1.00 & $3.59 \mathrm{E}-01$ \\
\hline GRS230 & RSp0842 & 1.17 & 2.12E-01 & 0.16 & 3.81E-07 \\
\hline GRS138 & GALA7 & 1.07 & $4.28 \mathrm{E}-01$ & 0.93 & $2.25 \mathrm{E}-01$ \\
\hline GRS99 & $a v r A$ & 0.16 & 6.85E-07 & 1.08 & $4.03 \mathrm{E}-01$ \\
\hline GRS76 & RSp0099 & 1.23 & $3.71 \mathrm{E}-01$ & 0.95 & $2.46 \mathrm{E}-01$ \\
\hline
\end{tabular}

${ }^{a}$ Values in bold indicate which results have been shown by statistical analysis to be significantly different from 1.0, as established using Student's $t$ test $(P$ value $<0.05$ ). 
ficities and representative of the biodiversity of the species (Guidot et al. 2007; Poueymiro and Genin 2009).

In summary, in vivo competition experiments demonstrate that growth defects can be detected and quantified for individual $R$. solanacearum T3E mutants. It also shows that many T3E probably contribute collectively to bacterial fitness in planta because the strongest attenuations detected in this study (avrA on tomato, RSp0842 on bean, and RSp0304 on eggplant) remain relatively modest compared with the attenuation observed with the hrp mutant strain (Tables 2 and 3). Nevertheless, this quantitative assay should provide a means to discriminate among the large $R$. solanacearum T3E repertoire those having the greatest impact on fitness on a specific host. This knowledge will be used in the future for cumulative gene disruption approaches in order to demonstrate functional redundancy or functional independence of different T3E.

\section{MATERIALS AND METHODS}

Plant material, bacterial strains, and growth conditions.

The bacterial strains used for this study are described in Table 1. $R$. solanacearum was grown in complete medium BG (Plener et al. 2010) at $28^{\circ} \mathrm{C}$. When required, antibiotics were used at the following concentrations: kanamycin, $50 \mathrm{mg} / \mathrm{liter}$; gentamicin, $10 \mathrm{mg} / \mathrm{liter}$; and spectinomycin, $50 \mathrm{mg} / \mathrm{liter}$. The plants used in this study were eggplant (Solanum melongena cv. Zebrina), tomato (Lycopersicum esculentum cv. SuperMarmande), and bean (Phaseolus vulgaris cv. Blanc précoce).

\section{Leaf infiltration CI assays.}

CI assays to measure growth attenuation were performed as previously described (Macho et al. 2007). Four- to five-week-old plants (for tomato and eggplant) and 15- to 20-day-old bean plants were used for the inoculations. Expanded leaves were inoculated by infiltration of $100 \mu \mathrm{l}$ of a $10^{4} \mathrm{CFU} / \mathrm{ml}$ mixed bacterial suspension, containing equal CFU of wild-type and mutant strains, using a blunt syringe. Serial dilutions of the inoculum were plated onto BG medium with and without the corresponding antibiotic to confirm the concentration of the inoculum and the relative proportion between the strains, which should be close to one. Plants were incubated in a growth chamber under cycles of $12 \mathrm{~h}$ of light and $12 \mathrm{~h}$ of darkness at $28^{\circ} \mathrm{C}$ and $70 \%$ humidity. At 5 dpi, inoculated leaves were harvested, weighed, and homogenized by mechanical disruption in a mortar, adding sterile water at $4 \mathrm{ml} / \mathrm{mg}$ of leaf tissue. Then, bacteria were enumerated by plating serial dilutions onto complete medium BG with and without the corresponding antibiotic, to differentiate the strains within the mixed infection. A CI in a mixed infection was defined as the mutant/wild-type ratio within the output sample divided by the corresponding ratio in the inoculum (Baümler et al. 1997).

\section{Pathogenicity assays and inoculation procedures.}

For soil-drenching inoculations, $50 \mathrm{ml}$ of a water suspension containing concentrations of washed bacteria ranging from $5 \times$ $10^{7}$ to $5 \times 10^{6} \mathrm{CFU} / \mathrm{ml}$ was poured over the soil. For stem injection, $10 \mu \mathrm{l}$ of bacterial suspensions ranging from $10^{6}$ to $10^{4}$ $\mathrm{CFU} / \mathrm{ml}$ was injected directly into the stem with a microsyringe (Hamilton, Reno, NV, U.S.A.). For each assay, inoculum concentrations were determined by plating serial dilutions onto BG medium with and without the appropriate antibiotic. Plants were incubated in a growth chamber under cycles of $12 \mathrm{~h}$ of light and $12 \mathrm{~h}$ of darkness at $28^{\circ} \mathrm{C}$ and $70 \%$ humidity. At $5 \mathrm{dpi}$, the aerial parts of the plants were harvested, weighed, and homogenized by mechanical disruption in a mortar, adding sterile water at 4 $\mathrm{ml} / \mathrm{mg}$ of plant tissue. Bacteria were then enumerated by plating serial dilutions onto BG medium with and without antibiotic.

\section{Statistical analysis.}

For each mutant strain and each plant tested, two or three independent competitive assays were conducted, each containing five plant replicates. For statistical analyses, CI values were first subjected to a square root transformation so that the values follow a normal distribution (Shapiro-Wilk normality test, $P$ value $>0.05)$. A one-way analysis of variance (ANOVA) was used to analyze the effect of the independent experiments on the $\mathrm{CI}$ values. Because no effect was detected (ANOVA, $P$ value $>0.05$ ), the values were pooled and the CI shown are the mean of the five replicates from every independent experiments. Each CI (square root transformed) was analyzed using Student's $t$ test and the null hypothesis: mean CI was not significantly different from $1(P$ value $=0.05$ was used).

\section{ACKNOWLEDGMENTS}

We thank C. Boucher and N. Peeters for helpful discussions. This research was supported by a short-term fellowship from the European Molecular Biology Organization (to A. P. Macho) and a French ANR grant D07 GMGE 003.

\section{LITERATURE CITED}

Aldon, D., Brito, B., Boucher, C., and Genin, S. 2000. A bacterial sensor of plant cell contact controls the transcriptional induction of Ralstonia solanacearum pathogenicity genes. EMBO (Eur. Mol. Biol. Organ.) J. 19:2304-2314

Allen, C., Prior, P., and Hayward, A. C. 2005. Bacterial wilt disease and the Ralstonia solanacearum species complex. American Phytopathological Society Press, St. Paul, MN, U.S.A.

Angot, A., Peeters, N., Lechner, E., Vailleau, F., Baud, C., Gentzbittel, L., Sartorel, E., Genschik, P., Boucher, C., and Genin, S. 2006. Ralstonia solanacearum requires F-box-like domain-containing type III effectors to promote disease on several host plants. Proc. Natl. Acad. Sci. U.S.A. 103:14620-14625.

Bai, J., Choi, S. H., Ponciano, G., Leung, H., and Leach, J. E. 2000. Xanthomonas oryzae pv. oryzae avirulence genes contribute differently and specifically to pathogen aggressiveness. Mol. Plant-Microbe Interact. 13:1322-1329.

Baümler, A. J., Tsolis, R. M., Valentine, P. J., Ficht, T. A., and Heffron, F. 1997. Synergistic effect of mutations in $i n v A$ and $l p f C$ on the ability of Salmonella typhimurium to cause murine typhoid. Infect. Immun. 65:2254-2259.

Beuzón, C. R., and Holden, D. W. 2001. Use of mixed infections with Salmonella strains to study virulence genes and their interactions in vivo. Microbes Infect. 3:1345-1352.

Boureau, T., El Maarouf-Bouteau, H., Garnier, A., Brisset, M. N., Perino, C., Pucheu, I., and Barny, M. A. 2006. DspA/E, a type III effector essential for Erwinia amylovora pathogenicity and growth in planta, induces cell death in host apple and nonhost tobacco plants. Mol. Plant-Microbe Interact. 19:16-24.

Carney, B. F., and Denny, T. P. 1990. A cloned avirulence gene from Pseudomonas solanacearum determines incompatibility on Nicotiana tabacum at the host species level. J. Bacteriol. 172:4836-4843.

Cunnac, S., Occhialini, A., Barberis, P., Boucher, C., and Genin, S. 2004. Inventory and functional analysis of the large Hrp regulon in Ralstonia solanacearum: identification of novel effector proteins translocated to plant host cells through the type III secretion system. Mol. Microbiol. 53:115-128.

Delaspre, F., Nieto Penalver, C. G., Saurel, O., Kiefer, P., Gras, E., Milon, A., Boucher, C., Genin, S., and Vorholt, J. A. 2007. The Ralstonia solanacearum pathogenicity regulator $\mathrm{HrpB}$ induces 3-hydroxy-oxindole synthesis. Proc. Natl. Acad. Sci. U.S.A. 104:15870-15875.

Denny, T. P. 2006. Plant pathogenic Ralstonia species. Pages 573-644 in: Plant-Associated Bacteria. S. S. Gnanamanickam, ed. Springer Publishing, Dordrecht, The Netherlands.

Deslandes, L., Pileur, F., Liaubet, L., Camut, S., Can, C., Williams, K. Holub, E., Beynon, J., Arlat, M., and Marco, Y. 1998. Genetic characterization of $R R S 1$, a recessive locus in Arabidopsis thaliana that confers resistance to the bacterial soilborne pathogen Ralstonia solanacearum. Mol. Plant-Microbe Interact. 7:659-667.

Deslandes, L., Olivier, J., Peeters, N., Feng, D. X., Khounlotham, M., Boucher, C., Somssich, I., Genin, S., and Marco, Y. 2003. Physical interaction between RRS1-R, a protein conferring resistance to bacterial 
wilt, and PopP2, a type III effector targeted to the plant nucleus. Proc. Natl. Acad. Sci. U.S.A. 100:8024-8029.

Freter, R., Allweiss, B., O’Brien, P. C., Halstead, S. A., and Macsai, M. S. 1981. Role of chemotaxis in the association of motile bacteria with intestinal mucosa: in vitro studies. Infect. Immun. 34:241-249.

Genin, S., and Boucher, C. 2002. Ralstonia solanacearum: secrets of a major pathogen unveiled by analysis of its genome. Mol. Plant Pathol. 3:111-118.

Genin, S., and Boucher, C. 2004. Lessons learned from the genome analysis of Ralstonia solanacearum. Annu. Rev. Phytopathol. 42:107-134.

Guéneron, M., Timmers, A.C., Boucher, C., and Arlat, M. 2000. Two novel proteins, PopB, which has functional nuclear localization signals, and PopC, which has a large leucine-rich repeat domain, are secreted through the hrp-secretion apparatus of Ralstonia solanacearum. Mol. Microbiol. 36:261-277.

Guidot, A., Prior, P., Schoenfeld, J., Carrère, S., Genin, S., and Boucher, C. 2007. Genomic structure and phylogeny of the plant pathogen Ralstonia solanacearum inferred from gene distribution analysis. J. Bacteriol. 189:377-387.

Jiang W., Jiang, B. L, Xu, R. Q., Huang, J. D., Wei, H. Y., Jiang, G. F., Cen, W. J., Liu, J., Ge, Y. Y., Li, G. H., Su, L. L., Hang, X. H., Tang, D. J., Lu, G. T., Feng, J. X., He, Y. Q., and Tang, J. L. 2009. Identification of six type III effector genes with the PIP box in Xanthomonas campestris pv. campestris and five of them contribute individually to full pathogenicity. Mol. Plant-Microbe Interact. 22:1401-1411.

Kearney, B., and Staskawicz, B. J. 1990. Widespread distribution and fitness contribution of Xanthomonas campestris avirulence gene avrBs2. Nature 346:385-386.

Lim, M. T., and Kunkel, B. N. 2005. The Pseudomonas syringae avrRpt2 gene contributes to virulence on tomato. Mol. Plant-Microbe Interact. 18:626-633.

Lorang, J. M., Shen, H., Kobayashi, D., Cooksey, D., and Keen, N. T. 1994 avrA and avrE in Pseudomonas syringae pv. tomato PT23 play a role in virulence on tomato plants. Mol. Plant-Microbe Interact. 7:508-515.

Losada, L., Sussan, T., Pak, K., Zeyad, S., Rozenbaum, I., and Hutcheson, S. W. 2004. Identification of a novel Pseudomonas syringae Psy61 effector with virulence and avirulence functions by a HrpL-dependent promoter-trap assay. Mol. Plant-Microbe Interact 17:254-262.

Macho, A. P., Zumaquero, A., Ortiz-Martin, I., and Beuzon, C. R. 2007. Competitive index in mixed infections: a sensitive and accurate assay for the genetic analysis of Pseudomonas syringae-plant interactions. Mol. Plant Pathol. 8:437-450.

Macho, A. P., Ruiz-Albert, J., Tornero, P., and Beuzon, C. R. 2009. Identification of new type III effectors and analysis of the plant response by competitive index. Mol. Plant Pathol. 10:69-80.

Mukaihara, T., and Tamura, N. 2009. Identification of novel Ralstonia solanacearum type III effector proteins through translocation analysis of $h r p B$-regulated gene products. Microbiology 155:2235-2244.

Occhialini, A., Cunnac S., Reymond N., Genin S., and Boucher C. 2005. Genome-wide analysis of gene expression in Ralstonia solanacearum reveals that the $h r p B$ gene acts as a regulatory switch controlling multiple virulence pathways. Mol. Plant-Microbe Interact. 18:938-949.

Plener, L., Manfredi, P., Valls, M., and Genin, S. 2010. PrhG, a transcriptional regulator responding to growth conditions, is involved in the control of the type III secretion system regulon in Ralstonia solanacearum. J. Bacteriol. 192:1011-1019.

Poueymiro, M., and Genin, S. 2009. Secreted proteins from Ralstonia solanacearum: a hundred tricks to kill a plant. Curr. Opin. Microbiol. 12:44-52.
Poueymiro, M., Cunnac, S., Barberis, P., Deslandes, L., Peeters, N., CazaleNoel, A. C., Boucher, C., and Genin S. 2009. Two Type III secretion system effectors from Ralstonia solanacearum GMI1000 determine host range specificity on tobacco. Mol. Plant-Microbe Interact. 22:538550.

Ritter, C., and Dangl, J. L. 1995. The avrRpm1 gene of Pseudomonas syringae pv. maculicola is required for virulence on Arabidopsis. Mol. Plant-Microbe Interact. 8:444-453.

Roberts, D. P., Denny, T. P., and Schell, M. A. 1988. Cloning of the egl gene from Pseudomonas solanacearum and analysis of its role in phytopathogenicity. J. Bacteriol. 170:1445-1451.

Saile, E., McGarvey, J. A., Schell, M. A., and Denny, T. P. 1997. Role of extracellular exopolysaccharide and endoglucanase in root invasion and colonization of tomato plants by Ralstonia solanacearum. Phytopathology 87:1264-1271.

Salanoubat, M., Genin, S., Artiguenave, F., Gouzy, J., Mangenot, S., Arlat, M., Billault, A., Brottier, P., Camus, J. C., Cattolico, L., Chandler, M. Choisne, N., Claudel-Renard, C., Cunnac, S., Demange, N., Gaspin, C. Lavie, M., Moisan, A., Robert, C., Saurin, W., Schiex, T., Siguier, P., Thebault, P., Whalen, M., Wincker, P., Levy, M., Weissenbach, J., and Boucher, C.A. 2002. Genome sequence of the plant pathogen Ralstonia solanacearum. Nature 415:497-502.

Schell, M. A. 2000. Control of virulence and pathogenicity genes of Ralstonia solanacearum by an elaborate sensory network. Annu. Rev. Phytopathol. 38:263-292.

Sequeira, L., and Hill, L. M. 1974. Induced resistance in tobacco leaves: the growth of Pseudomonas solanacearum in protected tissues. Physiol. Plant Pathol. 4:447-455.

Swarup, S., De Feyter, R., Brlansky, R. H., and Gabriel, D. W. 1991. A pathogenicity locus from Xanthomonas citri enables strains from several pathovars of $X$. campestris to elicit canker like lesions on citrus. Phytopathology 81:802-809.

Taylor, R. K., Miller, V. L., Furlong, D. B., and Mekalanos, J. J. 1987. Use of phoA gene fusions to identify a pilus colonization factor co-ordinately regulated with cholera toxin. Proc. Natl. Acad. Sci. U.S.A. 84:2833-2837.

Turner, M., Jauneau, A., Genin, S., Tavella, M. J., Vailleau, F., Gentzbittel, L., and Jardinaud, M. F. 2009. Dissection of bacterial wilt on Medicago truncatula revealed two type III secretion system effectors acting on root infection process and disease development. Plant Physiol. 150:1713-1722.

Vailleau, F., Sartorel, E., Jardinaud, M. F., Chardon, F., Genin, S., Huguet, T., Gentzbittel, L., and Petitprez, M. 2007. Characterization of the interaction between the bacterial wilt pathogen Ralstonia solanacearum and the model legume plant Medicago truncatula. Mol. Plant-Microbe Interact. 20:159-167.

Valls, M., Genin, S., and Boucher, C. 2006. Integrated regulation of the type III secretion system and other virulence determinants in Ralstonia solanacearum. PLoS Pathog. 2:798-807.

Vasse, J., Frey, P., and Trigalet, A. 1995. Microscopic studies of intracellular infection and protoxylem invasion of tomato roots by Pseudomonas solanacearum. Mol. Plant-Microbe Interact. 8:241-251.

Vasse, J., Genin, S., Frey, P., Boucher, C., and Brito, B. 2000. The hrpB and $h r p G$ regulatory genes of Ralstonia solanacearum are required for different stages of the tomato root infection process. Mol. Plant-Microbe Interact. 13:259-267.

Yao J., and Allen C. 2006. Chemotaxis is required for virulence and competitive fitness of the bacterial wilt pathogen Ralstonia solanacearum. J. Bacteriol. 188:3697-3708. 